\title{
Familial dilated cardiomyopathy with conduction defect due to LMNA mutation
}

INSERM

\section{Source}

INSERM. (1999). Orphanet: an online rare disease and orphan drug data base. Familial dilated cardiomyopathy with conduction defect due to LMNA mutation. ORPHA:300751

Familial dilated cardiomyopathy with conduction defect due to LMNA mutation is a rare familial dilated cardiomyopathy characterized by left ventricular enlargement and/or reduced systolic function preceded or accompanied by significant conduction system disease and/or arrhythmias including bradyarrhythmias, supraventricular or ventricular arrhythmias. Disease onset is usually in early to mid-adulthood. Sudden cardiac death may occur and may be the presenting symptom. In some cases, it is associated with skeletal myopathy and elevated serum creatine kinase. 